\title{
Nossas Águas, Nossos Rios: proposta de um $e$-book voltado à educação ambiental para as águas
}

\section{Decauita Poliana Peixoto da Silva ${ }^{1}, *$, Núbia Déborah Araújo Caramello ${ }^{1}$ e Patrícia Soares de Maria de Medeiros $^{2}$}

${ }^{1}$ Universidade Federal de Rondônia. Mestrado Profissional em Rede Nacional em Gestão e Regulação de Recursos Hídricos - ProfÁgua. Rua Rio Amazonas, 35. Jardim dos Migrantes. Ji-Paraná-RO, Brasil (CEP 76900-726). *E-mail: decauita@gmail.com.

${ }^{2}$ Universidade Federal de Rondônia. Departamento de Biologia. Rodovia BR-364, km 9,5. Porto Velho, R0, Brasill (CEP 76800-000).

Resumo. Em vista aos aspectos normativos e à necessidade da participação social para a efetiva gestão ambiental e dos recursos hídricos, a educação ambiental torna-se um veículo de instrumentalização da população sobre os impactos enfrentados pelos rios e igarapés. Desta forma, buscou-se realizar uma ação de educação ambiental como uma maneira de aproximação da população com os recursos hídricos locais e regionais do Município de Ji-Paraná, Rondônia, Brasil. Para tanto, foi desenvolvido um e-book sobre os recursos hídricos locais, direcionado a educadores ambientais, para que estes possam utilizar as informações no engajamento da comunidade sobre as questões relacionadas aos corpos hídricos do município. A elaboração do e-book foi direcionada para a localidade do Município de Ji-Paraná, parte central do Estado de Rondônia. 0 objetivo do presente trabalho foi descrever a metodologia utilizada na produção do $e$-book, de forma que possa fomentar a reprodução do método para outras localidades, destacando a relevância da educação ambiental para a gestão hídrica. Com o intuito de melhor instrumentalizar o educador em suas práticas de Educação Ambiental foram utilizados, no desenvolvimento do e-book, dados sobre estudos ambientais da região, sobretudo, das microbacias urbanas do Município de Ji-Paraná, entre 2010 e 2020 , coletados a partir de fontes oficiais, bem como de trabalhos científicos já desenvolvidos na região. Como resultado, observa-se que considerar a pesquisa científica regional proporciona a construção de um material didático a partir da realidade vivenciada dos atores, o que pode levar ao empoderamento nos diálogos participativos de gestão hídrica.

Palavras-chave: Bacia Hidrográfica do Rio Ji-Paraná; Gestão hídrica; Educação ambiental; Educação hídrica.

Recebido

$03 / 10 / 2020$

Aceito

$27 / 08 / 2021$

Publicado

$31 / 08 / 2021$

Acesso aberto

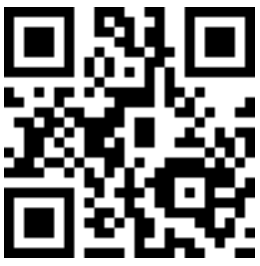

ORCID

(D) 0000-0002-1667-0346

Decauita Poliana

Peixoto da Silva

(1) 0000-0002-2167-9759

Núbia Déborah Araújo

Caramello

(ㄱ) 0000-0001-6245-6108

Patrícia Soares de

Maria de Medeiros 
Abstract. Our Waters, Our Rivers: Proposal for an e-book aimed at environmental education for waters. In view of the normative aspects and the need for social participation for effective environmental and water resources management, environmental education becomes a vehicle for instrumentalizing the population on the impacts faced by rivers and streams. Thus, we sought to carry out an environmental education action as a way of bringing the population closer to the local and regional water resources in the Municipality of Ji-Paraná, Rondônia, Brazil. To this end, an e-book on local water resources was developed, aimed at environmental educators, so that they can use the information in community engagement on issues related to water bodies in the municipality. The preparation of the e-book was directed to the locality of the Municipality of Ji-Paraná, central part of the State of Rondônia. The objective of the present work was to describe the methodology used in the production of the ebook, so that it can encourage the reproduction of the method for other locations, highlighting the relevance of environmental education for water management. In order to better equip the educator in his environmental education practices, data on environmental studies in the region were used in the development of the e-book, especially in the urban microbasins of the Municipality of Ji-Paraná, between 2010 and 2020, collected from official sources, as well as from scientific works already developed in the region. As a result, it is observed that considering regional scientific research provides the construction of didactic material from the reality experienced by the actors, which can lead to empowerment in participatory water management dialogues.

Keywords: Hydrographic Basin of the Ji-Paraná River; Water management; Environmental education; Water education.

\section{Introdução}

A implantação da gestão de recursos hídricos está vinculada a participação da sociedade, sendo este um dos maiores desafios da implantação de comitês de bacia hidrográfica no estado de Rondônia. A Educação Ambiental, pode ser conceituada como processo educativo formal e informal que empreende uma reflexão crítica sobre uma realidade objetiva, sendo numa proposta de formação conceitual pode contribuir para promover o desenvolvimento da consciência filosófica de um determinado tema (Maia e Teixeira, 2015). Assim, a habilitação de conhecimentos e habilidades visa dar a "base utilitária" e oferecer a possibilidade de a comunidade avaliar e controlar suas necessidades e ações de acordo com suas demandas (Biasoli e Sorrentino, 2018).

Por mais que a Lei no 9.433/1997 (Brasil, 1997), não disponha sobre a educação ambiental, ela pode configurar um instrumento de gestão ao estabelecer ampliação de acesso ao conhecimento contribuindo para o empoderamento, descentralização e participação social que podem ser fortalecidos por meio dela. Sobre essa temática, a Resolução no 98/2009, do Conselho Nacional de Recurso Hídricos, estabelece como um dos elementos orientadores a acessibilidade na comunicação das informações sobre os recursos hídricos. Nesse sentido, Diniz e Maranhão (2013, p. 78) destacam uma questão 
relevante: "como articular políticas e planejar ações de forma participativa e com controle público, sem informação e formação de atores diversos, fatores integrantes de processos educativos?"

A falta de participação e engajamento político da sociedade é um desafio histórico a ser vencido por meio de estratégias contínuas, e não somente por intermédio de projetos e ações isoladas (Santos et al., 2018). Relativamente a isso, Tonso (2013) aponta que a dificuldade em consolidar diálogos para a gestão hídrica, entre as diferentes camadas da sociedade, provém da desigualdade. A valorização da hierarquia do saber e do progresso provocam a homogeneização popular e a exclusão daquilo que é diferente, e, como consequência, o silenciamento social.

A abordagem para ensino do tema água e rios, sendo ambos de extrema relevância na região amazônica e ao ser trabalhado juntos aproxima de realidades vivenciadas sendo que os rios possuem muitos significados, deve estar focado também na formação ética do indivíduo, em que este seja consciente da relação estabelecida entre as suas próprias ações e o ambiente (Bacci e Pataca, 2008; López-Alcarria et al., 2014; Otto e Pensini, 2017). Desta forma, a educação hídrica não deve voltar-se tão somente para os usos, mas também para a percepção de que a água e os rios são elementos que fazem parte de um sistema muito maior, dinâmico e sujeito a alterações, principalmente àquelas provocadas pela ação humana.

A despeito da riqueza ambiental e hídrica, a região amazônica, em geral, sofre com impactos ambientais que podem ter implicações na disponibilidade hídrica, a exemplo da devastação florestal intensificada no arco do desmatamento e a precariedade do saneamento (Coutinho et al., 2017; Espindola et al., 2012). Nesse viés, o Município de JiParaná, no Estado de Rondônia, firma-se como reflexo dessa situação, ocorrida na grande parte da região. Estudos como os de Nascimento et al. (2020), Ruezenne et al. (2019) e Valadão et al. (2019) já acusam indícios de diferenciação nas variáveis hidroclimáticas (umidade do ar, precipitação e evapotranspiração) entre áreas de floresta e pastagem na Bacia do Rio Ji-Paraná.

Além do que, por conta das condições inadequadas do saneamento e uso e ocupação, análises de qualidade da água confirmam a alteração das condições naturais das águas em igarapés do município, devido a aspectos que são naturalmente perceptíveis, a exemplo da degradação das áreas de preservação permanente dos igarapés, emissão direta de esgoto e de resíduos sólidos, assoreamento, dentre outros (Araújo, et al., 2018; Rocha e Andrade, 2018; Santos et al., 2019; Silva et al., 2019; Souza et al., 2019).

Contudo, nos últimos anos, o Estado de Rondônia tem dado passos importantes no gerenciamento de recursos hídricos, como por exemplo no monitoramento e divulgação de dados de qualidade da água e na instituição de cinco comitês de bacia hidrográfica, todos instituídos no ano de 2014 (ANA, 2016). Destes, três estão em funcionamento (Rio Branco e Colorado; São Miguel e Guaporé; e Jamari) e dois estão em processo de mobilização (Gonçalves et al., 2019) entres eles os comitês do Alto e Médio Machado, onde está inserido o Município de Ji-Paraná, foco de atenção deste estudo, e o Comitê do Rio Jaru - Baixo Machado. No caso dos comitês, tem fundamental importância a participação popular, uma vez que os recursos hídricos são bem públicos e devem ser geridos observando as demandas da sociedade de forma democrática, como preconiza a Lei $\mathrm{n}$ o 9.433/1997 (Brasil, 1997). Desse modo, evidencia-se a importância da aproximação social para a gestão dos recursos hídricos no estado, pois são os usuários diretos e formadores de opinião que poderão trazer as demandas locais e específicas (Rondônia, 2018).

A educação ambiental voltada à bacia hidrográfica é uma lacuna no Estado de Rondônia (Caramello et al., 2020). Fato que se torna mais evidente com estudo pontual desenvolvido por Silva et al. (2020), ao entrevistar professores da rede pública estadual do Município de Ji-Paraná, identificou que há um grande desconhecimento a respeito da gestão de recursos hídricos do Estado de Rondônia e ausência temática nas escolas 
analisadas. Ao serem questionados se são realizados projetos ou atividades contínuas voltadas para a sustentabilidade ambiental ou dos recursos hídricos, somente 14,3\% dos professores entrevistados responderam que sim. Sobre o incentivo recebido para realização de atividades obteve-se 7,1\% afirmativo, evidenciando a relevância de ações voltadas a esse público e outros formadores de opinião. Um fator que que motiva preparar um material que possa ser útil a capacitação, ocorre quando $71,4 \%$ afirmam ter interesse em partir de cursos de formação relacionado a temática.

Nesse sentido, desenvolveu-se um material informativo digital (e-book) direcionado a educadores ambientais, sendo estes professores ou de outros setores da sociedade, com o propósito de atuar como material didático que auxilie o acesso à informação sintetizada e atualizada, na perspectiva da contextualização do conhecimento dos recursos hídricos da região. Este material contempla resultados de pesquisas científicas locais já realizadas e proporciona fontes de pesquisa e metodologias possíveis de serem realizadas com foco nos recursos hídricos locais. 0 objetivo do presente trabalho é reforçar a relevância da Educação Ambiental como instrumento de gestão de recursos hídricos e descrever a metodologia utilizada na produção do $e$-book, de forma que possa fomentar a reprodução do método para outras localidades e evidenciar as possibilidades da contribuição de um programa de mestrado profissional.

\section{Material e métodos}

\section{Área de desenvolvimento}

A elaboração do $e$-book foi direcionada para o município de Ji-Paraná, localizado na parte central do estado de Rondônia, região Norte do Brasil, com população estimada em aproximadamente 129.000 habitantes (IBGE, 2020). 0 município está situado no interior da Bacia Hidrográfica do Rio Ji-Paraná (também conhecido como Rio Machado), afluente do Rio Madeira, margem direita do Rio Amazonas. A classe de uso e ocupação predominante na bacia é a pastagem, sendo que a porção vegetada é composta por floresta ombrófila aberta, concentrada, principalmente, no interior da Reserva Biológica do Rio Jaru (ReBio-Jaru) e na porção próxima à foz da bacia. A precipitação média anual da bacia varia de 1900 a 2200 mm (ANA, 2012; Silva e Lima, 2019).

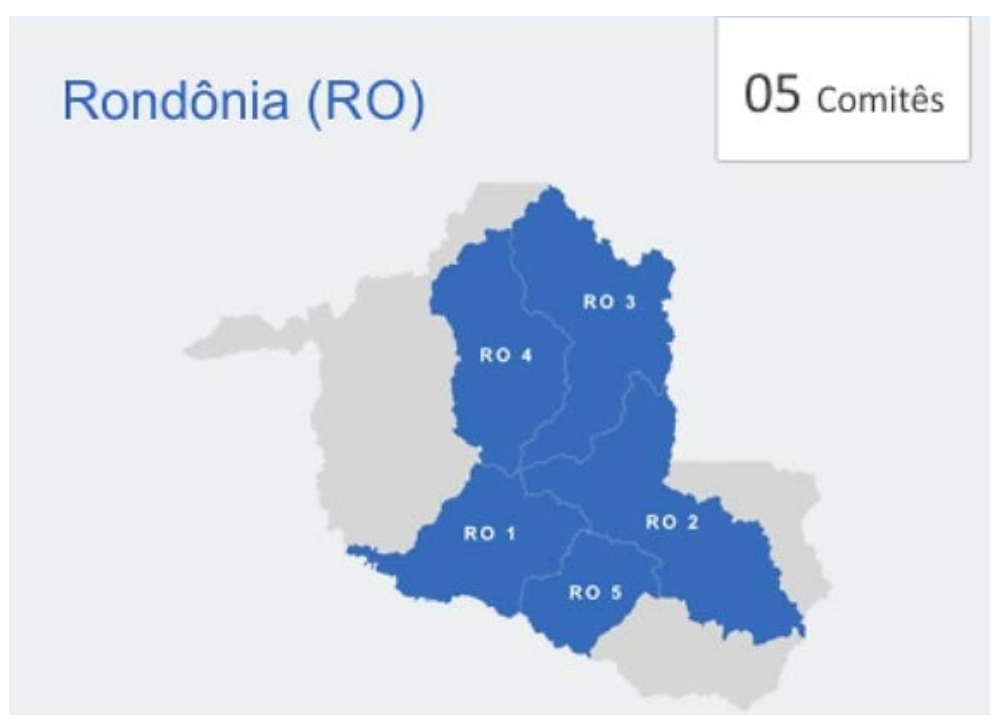

Figura 1. Comitês de bacias hidrográficas instituídos no Estado de Rondônia. RO1 - CBH do Rio São Miguel - Vale do Guaporé; RO2 - CBH do Rio Alto e Médio Machado; RO3 - CBH do Rio Jaru - Baixo Machado; RO4 - CBH do Rio Jamari; e RO5 - CBH dos Rios Branco e Colorado. Fonte: ANA (2020). 
Atualmente, o município ainda não tem implantado o sistema de coleta e tratamento de esgoto, embora o Plano Municipal de Saneamento Básico existente inclua esse elemento (Ji-Paraná, 2012). Além disso, conforme Gonçalves et al. (2019), apesar de terem sido instituídos pelo Decreto no 19.058/2014 dois comitês na Bacia do Rio Ji-Paraná (Rondônia, 2014), somente um deles está em processo de efetiva implantação, o CBH-Rio Jaru-Baixo Machado. Ao todo, são cinco comitês instituídos no Estado de Rondônia (Figura 1).

\section{E-book}

No desenvolvimento do e-book foram utilizados dados sobre os recursos hídricos do Município de Ji-Paraná, coletados a partir de fontes oficiais, bem como de artigos científicos, de forma a fomentar a visibilidade e a popularização das pesquisas realizadas no município pela Universidade Federal de Rondônia, em seus cursos de graduação e pósgraduação. Foram priorizadas as pesquisas em bacias hidrográficas locais, qualidade da água de igarapés urbanos, análises ambientais relacionadas aos recursos hídricos e sobre gestão de recursos hídricos.

Desta forma, o primeiro passo na elaboração do $e$-book foi a pesquisa bibliográfica e documental. As principais fontes de busca utilizadas foram as bibliotecas digitais Scientific Electronic Library Online (SciELO) e o portal Periódicos CAPES, bem como o repositório Google Acadêmico. Devido à grande quantidade de trabalhos já desenvolvidos, foi delimitado o período de pesquisa para trabalhos publicados entre 2010 e 2020.

0 segundo passo da elaboração do $e$-book consistiu na separação e sequenciação dos capítulos, juntamente com a estruturação dos tópicos a serem abordados no material.

Por último, a edição e revisão do e-book foram realizadas utilizando-se recursos gráficos como imagens, organogramas, ilustrações, mapas temáticos, gráficos etc., a fim de tornar as informações mais atrativas e didáticas, visto que uma das finalidades do material é tornar o conteúdo mais acessível para que educadores possam aplicar as informações em sala de aula e para a comunidade em geral. Todas as fases da construção do produto foram submetidas a uma avaliação ad hoc, realizada por pesquisadores com o título de doutores com experiência em produção de material didático, na atuação de educação ambiental e mobilização de comitês de bacia hidrográfica.

Devido às adaptações sociais em decorrência da pandemia da Covid-19, a oficina de formação prevista e a divulgação do $e$-book, não pôde ser realizada presencialmente. Desta forma, até que a situação seja normalizada, a distribuição do e-book e diálogos voltados à motivação do acesso ao conteúdo será realizada por meio digital.

\section{Resultados}

0 conteúdo abordado no e-book evidencia aspectos referentes à educação ambiental, à sua função na educação sobre os corpos d'água e os resultados dos estudos locais. Na Tabela 1 estão dispostos os tópicos abordados em cada capítulo do e-book.

Iniciou-se o conteúdo do e-book (Capítulo 1) por meio de uma breve explanação sobre conceitos e histórico da educação ambiental. No mesmo capítulo foi introduzida a importância da educação ambiental para a sensibilização de participação social em políticas públicas e, principalmente, na gestão da água (Figura 2a).

No Capítulo 2 foram dispostas fontes de pesquisa, estudos, metodologias e práticas que podem ser utilizadas na abordagem da bacia hidrográfica (Figura 2b). Destaca-se que foram espacializadas as escolas dentro dos dados vetoriais das microbacias de Ji-Paraná, de forma a facilitar a procura de informações sobre a microbacia na qual cada escola está situada (Figura 2c). 
Tabela 1. Divisão temática dos tópicos abordados no $e$-book.

\begin{tabular}{|c|c|c|}
\hline Capítulo & Tema & Tópicos \\
\hline 1 & $\begin{array}{c}\text { Educação para a } \\
\text { Sustentabilidade } \\
\text { Ambiental }\end{array}$ & $\begin{array}{l}\text { - A origem da EA como campo de estudo; } \\
\text { - Educação Ambiental no ensino básico; } \\
\text { - Educação Ambiental e a gestão dos recursos hídricos; } \\
\text { - O diálogo entre a teoria e a realidade; } \\
\text { - A gestão da água em Rondônia }\end{array}$ \\
\hline 2 & $\begin{array}{l}\text { Educação para } \\
\text { as Águas: } \\
\text { recursos } \\
\text { orientadores }\end{array}$ & $\begin{array}{l}\text { - Capacitação de educadores ambientais; } \\
\text { - EaD - ANA; } \\
\text { - O diálogo entre a teoria e a realidade; } \\
\text { - Abordagens para a EA em recursos hídricos: } \\
\text { - Fontes de pesquisa } \\
\text { - Algumas Metodologias... } \\
\text { - Cartilhas educativas }\end{array}$ \\
\hline 3 & $\begin{array}{l}\text { Conhecendo um } \\
\text { pouco mais } \\
\text { sobre nossos } \\
\text { recursos } \\
\text { hídricos... }\end{array}$ & $\begin{array}{l}\text { - Amazônia: maior bacia hidrográfica do mundo! } \\
\text { - Alterações no uso do solo e suas implicações para os recursos } \\
\text { hídricos; } \\
\text { - Impactos em Áreas de Preservação Permanente; } \\
\text { - Saneamento; } \\
\text { - Manancial de abastecimento: Rio Urupá. }\end{array}$ \\
\hline
\end{tabular}
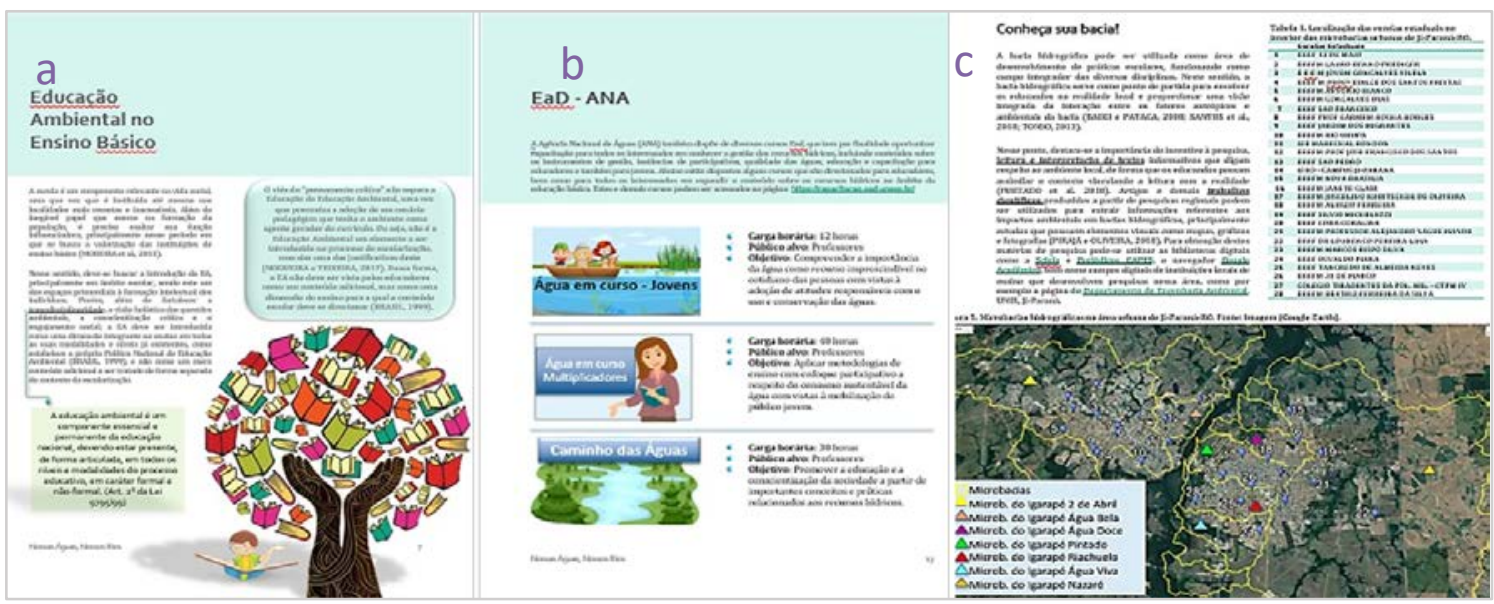

Figura 2. Ilustração de algumas páginas dos e-book: a) Capítulo 1, p. 7; b) Capítulo 2, p. 14; c) Capítulo 2, p. 16.

No terceiro e último capítulo foram dispostos resultados de pesquisas científicas sobre os recursos ambientais e hídricos, prioritariamente da bacia do rio Ji-Paraná-RO e dos igarapés urbanos do município (Figura 3).

Ao todo foram encontrados 42 trabalhos publicados em periódicos científicos, eventos acadêmicos ou livros digitais, sendo duas análises morfométricas, duas análises de saneamento, oito análises de uso e ocupação, duas análises climáticas, quatro análises de variáveis hidrológicas, 19 análises de qualidade da água superficial, bem como cinco análises de qualidade da água subterrânea. 


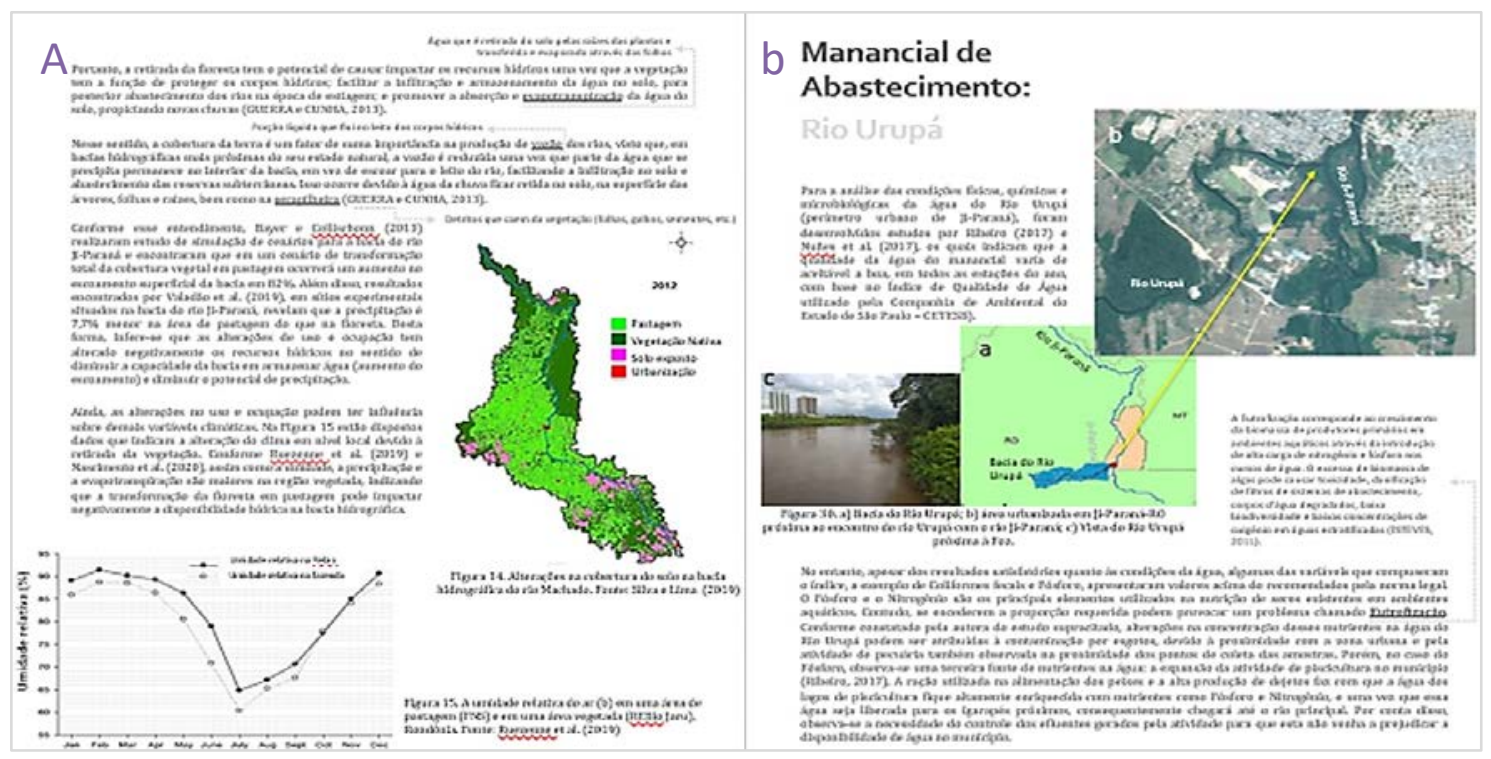

Figura 3. Ilustração de páginas do Capítulo 3 do e-book: a) p. 25; b) p. 31.

Buscou-se tornar o conteúdo do e-book o mais sucinto possível, porém sem perder a qualidade da informação cientifica. Assim sendo, devido à grande quantidade de informações obtidas, foram somente considerados trabalhos publicados e monografias que não originaram publicações até o momento. Contudo, ainda assim, nem todos os trabalhos puderam ser incluídos no e-book, de forma que foram selecionados os trabalhos mais atualizados ou que se destacaram devido à temática ou aos resultados.

\section{Discussão}

Ao longo da história da existência humana, todos os aspectos ligados à água foram determinantes para a ocupação de territórios, para a formação de hábitos culturais, para o surgimento de conflitos, dentre outros. Ao longo do processo de apropriação da água disponível, esta passou a ser vista mais como um recurso rentável e menos como elemento primordial à manutenção do ecossistema (Bacci e Pataca, 2008). Não que esse não seja um aspecto importante, uma vez que desempenha condição primordial para o desenvolvimento do país, mas deve-se levar em conta também os demais aspectos essenciais relativos à água (De Paula-Júnior, 2013).

Os impactos relativos aos recursos hídricos não são percebidos somente quanto ao aspecto físico, mas principalmente quanto à relação cultural dos grupos sociais com 0 elemento água. Têm ocorrido profundas alterações no ciclo hidrossocial. Sobre este aspecto, Tonso (2013) destaca que a dimensão política e social relacionada às desigualdades e à heterogeneidade de tratamento da água pelos diversos grupos e culturas sociais deve tomar prioridade no enfrentamento da degradação hídrica.

A Lei no 9.433/1997 indica que o gerenciamento dos recursos hídricos deve contar com a participação da comunidade e traz como um dos principais meios de participação social os comitês de bacia hidrográfica, que devem ser compostos por membros do Poder Público, dos usuários e da sociedade civil organizada (Brasil, 1997), sendo as escolas, comunidades ribeirinhas possíveis atores representativos e multiplicadores de informação.

No entanto, como apontado por Berlink e Saito (2010), "entre as três esferas sociais, a sociedade civil geralmente é o elo mais fraco, devido à sua falta de conhecimento 
científico-tecnológico que permita ou motive sua participação concreta nos debates racionais que ocorrem no Comitê". Ainda conforme os autores, a participação da sociedade civil organizada nos comitês de bacia é, predominantemente, próxima ao mínimo exigido, que é de $20 \%$.

Assim sendo, destaca-se também a importância não só de ampliar a participação social na gestão ambiental, como também de aprofundar a qualidade dessa participação, de forma a melhorar a representatividade nos comitês de bacia (Epengler, 2013). Nesse sentido, são apontados desafios para a consolidação do Plano Nacional de Recursos Hídricos, sendo estes a implantação da gestão integrada por bacia hidrográfica; a mobilização e participação nos fóruns de recursos hídricos; a inclusão da gestão hídrica como prioridade na agenda de políticas públicas (Tonso, 2013).

Deste modo, a habilitação de conhecimentos e habilidades assume o seu lado político, justificado apenas se o uso da informação autoriza o controle e a transformação de sua realidade. Ações educativas visam a dar a "base utilitária" e oferecer a possibilidade de a comunidade avaliar e controlar suas necessidades e ações de acordo com suas demandas. Métodos educativos que propiciem a espacialização dos elementos da paisagem e auxiliem na visualização integral dos aspectos de uso e ocupação dentro de bacias hidrográficas corroboram para a compreensão da comunidade das preocupações básicas da gestão dos recursos hídricos (Biasole e Sorrentino, 2018).

Portanto, evidencia-se a função primordial da educação ambiental para o fortalecimento do cunho ambiental no âmbito da Política Nacional de Recursos Hídricos e, ao mesmo tempo, proporciona interligação entre os diversos elementos que compõe as políticas ambientais e o Sistema Nacional de Meio Ambiente (SISNAMA) e Sistema Nacional de Gerenciamento dos Recursos Hídricos (SINGREH). Além disso, contribui para percepção da importância estratégica da água nas políticas ambientais e para o aprofundamento da gestão democrática da água (De Paula-Júnior e Modaelli, 2013).

A institucionalização da Educação Ambiental no contexto da Política Nacional de Recursos Hídricos só ocorreu efetivamente a partir da criação da Câmara Técnica de Educação, Capacitação Social e Informação em Recursos Hídricos pela Resolução nº 39 do CNRH (De Paula-Júnior e Modaelli, 2013). Atualmente, à medida que as políticas públicas foram sendo reformuladas e implantadas, observou-se a incorporação da garantia da participação social. Porém a efetividade da participação da sociedade no âmbito destas políticas é um fator ainda precário (Picolli et al., 2017).

No contexto do espaço escolar, Bacci e Pataca (2008) sugerem, como forma de introduzir a educação para a água, que sejam construídos programas que tenham a água como principal temática e que sejam apoiados por todos os educadores, com envolvimento coletivo, diálogo, trocas de conhecimento, sobretudo que se estabeleça a relação entre o tema e a prática pedagógica, não meramente como atividades à parte do projeto curricular. É preciso que se compreenda a necessidade de incorporar esta matéria ao conteúdo regular. Caramello et al. (2020) reforça essa questão ao pontual que a Secretaria de Educação do Estado de Rondônia, deve assumir o compromisso de formar professores para a participação no diálogo hídrico e nas agendas ambientais internacionais.

Além disso, Piza e Téran (2016) destacam a importância de que os educadores busquem outras fontes de informação para as aulas, uma vez que os livros didáticos possuem conteúdo muito superficial e restrito sobre a temática da água. Geralmente não são abordados assuntos locais ou regionais. Por outro lado, o material didático aborda a região amazônica, prioritariamente, na visão de abundância hídrica, tornando mais difícil a percepção dos educandos quanto à necessidade de preservação dos corpos d'água.

Desta forma, tornam-se válidos os esforços e instrumentos que objetivam aproximar a comunidade das informações técnicas disponíveis sobre os recursos ambientais e hídricos locais. Por si só, a existência de estudos, análises e pesquisas não garante o repasse dessas informações para a população, visto que, na maioria das vezes a 
linguagem técnica é uma barreira à difusão desse conhecimento. Para tanto, tais informações devem ser adequadas às diversas camadas e setores da comunidade civil, que não só deve, mas tem o direito de conhecer mais a fundo sua própria realidade.

\section{Conclusões}

Apesar da amplitude do escopo inerente à gestão ambiental, faz-se mister concentrar esforços em áreas estratégicas, a exemplo dos recursos hídricos, uma vez que são elementos naturais fundamentais aos diversos usos. Além disso, a atual urgência em tratar dessa temática gira em torno, não somente dos conflitos pelo uso, mas também dos problemas com eventos extremos de escassez e inundações, que estão ficando cada vez mais intensas, e com desastres naturais ou antrópicos envolvendo este recurso.

Deve-se destacar, também, a relevância da realização do estudo das questões ambientais, mais precisamente, às relativas aos recursos hídricos, por meio de um material didático que contextualize a região na qual o educando se encontra, no qual ele poderá perceber aspectos relevantes da realidade do ambiente em que vive. Visto isso, espera-se que o conteúdo deste material possa incentivar educadores ambientais, professores do ensino básico ou não, à sensibilização de educandos e da comunidade em geral e possa, ainda, contribuir em sua prática de educação ambiental para as águas.

\section{Agradecimentos}

Ao Programa de Mestrado Profissional em Rede Nacional em Gestão e Regulação de Recursos Hídricos - ProfÁgua, Projeto CAPES/ANA AUXPE no 2717/2015. Ao campus JiParaná da Fundação Universidade Federal de Rondônia.

\section{Conflitos de Interesses}

As autoras declaram não haver conflitos de interesses.

\section{Referências}

ANA - Agência Nacional de Águas e Saneamento Básico. Comitês por Região. Disponível em: <https://www.ana.gov.br/aguas-no-brasil/sistema-de-gerenciamento-de-recursoshidricos/comites-de-bacia-hidrografica/rondonia>. Acesso em: 07 ago. 2020.

ANA - Agência Nacional de Águas. Plano estratégico de recursos hídricos dos afluentes da margem direita do Rio Amazonas: resumo executivo. Brasília: ANA, 2012. Disponível em: <http://arquivos.ana.gov.br/institucional/sge/CEDOC/Catalogo/2013/ planoEstrategicoDeRecursos.pdf>. Acesso em: 11 dez. 2019.

ANA - Agência Nacional de Águas. Contrato no 031/2016. Contrato que entre si celebram a ANA e a SEDAM, objetivando a concessão de estímulo financeiro pelo alcance de metas de monitoramento e divulgação de dados de qualidade de água. Diário Oficial da União, no 161,22 de agosto de 2016.

Araújo, R. R.; Andrade, N. L. R.; Ribeiro, J. G. S. Uso e ocupação do solo em áreas de preservação permanente do Município de Ji-Paraná-RO. Anais do IX Congresso Brasileiro de Gestão Ambiental, São Bernardo do Campo, 2018.

Bacci, D. C.; Pataca, E. M. Educação para a água. Estudos Avançados, v. 22, n.63, p. 211-216, 2008. https://doi.org/10.1590/S0103-40142008000200014 
Berlinck, C. N.; Saito, C. H. Action research for emancipation informed by habermas and hierarchy of systems: Case study on environmental education and management of water resources in Brazil. Systemic Practice and Action Research, v. 23, n. 2, p. 143-156, 2010. https://doi.org/10.1007/s11213-009-9150-z

Biasoli, S.; Sorrentino, M. Dimensões das políticas públicas de educação ambiental: a necessária inclusão da política do cotidiano. Ambiente \& Sociedade, v. 21, 2018. https://doi.org/10.1590/1809-4422asoc0144r2vu18l2ao

Brasil. Lei no 9.433, de 8 de janeiro de 1997. Institui a Política Nacional de Recursos Hídricos, cria o Sistema Nacional de Gerenciamento de Recursos Hídricos, regulamenta o inciso XIX do art. 21 da Constituição Federal, e altera o art. 1ํ da Lei $\mathrm{n}^{\circ}$ 8.001, de 13 de março de 1990, que modificou a Lei no 7.990, de 28 de dezembro de 1989. Disponível em: <http://www.planalto.gov.br/ccivil_03/leis/19433.htm>. Acesso em: 11 dez. 2019.

Brasil. Lei no 9.795, de 27 de abril de 1999. Dispõe sobre a educação ambiental, institui a Política Nacional de Educação Ambiental e dá outras providências. Disponível em: <http://www.planalto.gov.br/ccivil_03/leis/19795.htm>. Acesso em: $11 \mathrm{dez} .2019$.

Brasil. Resolução CNRH no 98, de 26 de março de 2009. Estabelece princípios, fundamentos e diretrizes para a educação, o desenvolvimento de capacidades, a mobilização social e a informação para a Gestão Integrada de Recursos Hídricos no Sistema Nacional de Gerenciamento de Recursos Hídricos. Disponível em: <https://cnrh.mdr.gov.br/resolucoes/902-resolucao-cnrh-n-98-de-26-de-marco-de2009/file>. Acesso em: 11 dez. 2019.

Caramello, N.; Martins, I.; Silva, F. M.; Reis, M. C. O.; Silva, D. P. P.; Ferreira, M. M. A SeducRondônia como instrumento de gestão de recursos hídricos frente às diretrizes internacionais para a sustentabilidade. In: Albuquerque, C. C.; Batista, I. H. (Org.). Workshop internacional sobre planejamento e desenvolvimento sustentável em bacias hidrográficas. 1. ed. Boa Vista: Editora da UFRR, 2020. v. 1. p. 1460-1472.

Coutinho, E. D. C.; Rocha, E. J. P. D.; Lima, A. M. M.; Ribeiro, H. M. C.; Gutierrez, L. A. C. L.; Barbosa, A. J. S.; Paes, G. K. A. A.; Bispo, C. J. C.; Tavares, P. A. Riscos socieconômicos e ambientais em municípios banhados pelos afluentes do Rio Amazonas. Revista Ambiente e Água, v. 12, n. 5, p. 814-828, 2017. https://doi.org/10.4136/ambi-agua.2013

De Paula-Júnior, F.; Modaelli, S. (Orgs.). Política de águas e educação ambiental: processos dialógicos e formativos em planejamento e gestão de recursos hídricos. Brasília: MMA/SRHU, 2013.

De Paula-Júnior, F. Formação, diálogo e participação no planejamento e gestão das águas. In: Paula-Júnior, F.; Modaelli, S. (Orgs.). Política de águas e educação ambiental: processos dialógicos e formativos em planejamento e gestão de recursos hídricos. Brasília: MMA/SRHU, 2013.

Diniz, N. S. M.; Maranhão, R. R. Educação ambiental, participação e gestão das águas. In: Paula-Júnior, F.; Modaelli, S. (Orgs.). Política de águas e educação ambiental: processos dialógicos e formativos em planejamento e gestão de recursos hídricos. Brasília: MMA/SRHU, 2013.

Epengler, E. Os desafios da educação ambiental para a participação social na gestão ambiental e de recursos hídricos. In: Paula-Júnior, F.; Modaelli, S. (Orgs.). Política de águas e educação ambiental: processos dialógicos e formativos em planejamento e gestão de recursos hídricos. Brasília: MMA/SRHU, 2013. 
Espindola, G. M.; Aguiar, A. P. D.; Pebesma, E.; Câmara, G.; Fonseca, L. Agricultural land use dynamics in the Brazilian Amazon based on remote sensing and census data. Applied Geography, v. 32, n. 2, p. 240-252, 2012. https://doi.org/10.1016/j.apgeog.2011.04.003

Gonçalvez, A. P. A.; Zuffo, C. E.; Goveia, G. R. T. A importância dos municípios na gestão das águas através dos Comitês de Bacias Hidrográficas, o caso do CBH-JBM-RO. Anais do XVIII Simpósio Brasileiro de Geografia Física Aplicada, Fortaleza, 2019.

IBGE - Instituto Brasileiro de Geografia e Estatística. IBGE Cidades. 2020. Disponível em: <https://cidades.ibge.gov.br/brasil/ro/ji-parana/panorama>. Acesso em: 22 maio 2020.

Ji-Paraná. Plano Municipal de Saneamento Básico. Ji-Paraná: Prefeitura Municipal de Ji-Paraná, 2012. (Relatório final).

López-Alcarria, A.; Gutiérrez-Pérez, J.; Poza-Vilches, F. Preschool education professionals as mediators of environmental health education. Procedia - Social and Behavioral Sciences, v. 132, p. 639-646, 2014. https://doi.org/10.1016/j.sbspro.2014.04.366

Maia, J. S. S.; Teixeira, L. A. Formação de professores e educação ambiental na escola pública: contribuições da pedagogia histórico-crítica. HISTEDBR, n. 63, p. 293-305, 2015.

Nascimento, J. S. M. D.; Aguiar, R. G.; Fischer, G. R.; Andrade, N. L. R. D.; Aguiar, L. J. G.; Webler, A. D Mudanças no uso da terra na Amazônia Ocidental e a resposta do microclima à ocorrência de eventos extremos. Revista Brasileira de Meteorologia, v. 35, n. 1, p. 135-145, 2020. https://doi.org/10.1590/0102-7786351009

Otto, S.; Pensini, P. Nature-based environmental education of children: Environmental knowledge and connectedness to nature, together, are related to ecological behavior. Global Environmental Change, v. 47, p. 88-94, 2017. https://doi.org/10.1016/ j.gloenvcha.2017.09.009

Piccoli, A. S.; Kligerman, D. C.; Cohen, S. C. Políticas em saúde, saneamento e educação: trajetória da participação social na saúde coletiva. Saúde e Sociedade, v. 26, n. 2, p. 397-410, 2017. https://doi.org/10.1590/S0104-12902017160043

Piza, A. A. P.; Téran, A. F. Ensinando sobre a conservação dos recursos hídricos em espaços educativos. In: Téran, A. F.; Santos, S. C. S. Temas sobre ensino de Ciências em espaços não formais: avanços e perspectivas. Manaus: UEA Edições, 2016.

Rocha, V. N. L.; Andrade, N. R. A. Relação entre índice de qualidade das águas e densidade demográfica dessimétrica em igarapés urbanos amazônicos. Revista Ibero-Americana de Ciências Ambientais, v. 9, n. 2, p. 148-159, 2018. https://doi.org/10.6008/CBPC21796858.2018.002.0013

Rondônia. Decreto no 19.058, de 31 de julho de 2014. Institui o Comitê da Bacia Hidrográfica do Rio Alto e Médio Machado - CBH-AMMA-RO e dá outras providências. Disponível em: <http://ditel.casacivil.ro.gov.br/COTEL/Livros/Files/DEC19058.pdf>. Acesso em: 13 nov. 2019.

Rondônia. Plano Estadual de Recursos Hídricos do Estado de Rondônia. 2018. Disponível em: <http://www.sedam.ro.gov.br/index.php/downloads.html?showall= \&start=5>. Acesso em: 13 nov. 2019.

Ruezzene, C. B.; Parizotto, D.; Cidin, A. C.; Pinto, T. J. S.; Oliveira, D.; Crestana, S.; Miranda, R. B.; Mauad, F. F. Water balance and net radiation in forest and pasture area in Southwest Amazon. Revista Eletrônica em Gestão, Educação e Tecnologia Ambiental, v. 23, p. 37, 2019. https://doi.org/10.5902/2236117039840 
Santos, C. R.; Grilli, N. M.; Ghilardi-Lopes, N. P. A collaborative work process for the development of coastal environmental education activities in a public school in São Sebastião (São Paulo State, Brazil). Ocean \& Coastal Management, v. 164, p. 147-155, 2018. https://doi.org/10.1016/j.ocecoaman.2017.08.011

Santos, S.; Muniz, C. K. D.; Ferreira, D. B.; Rosa, N. B.; Queiroz, M. D. L. N.; Ferreira, A. S.; Gomes, F. T. A.; Vallejo, N. M. Perfil do diagnóstico de casos notificados de leptospirose em um município da Amazônia Legal. South American Journal of Basic Education, Technical and Technological, v. 6, n. 1, p. 227-243, 2019.

Silva, D. P. P.; Andrade, N. L. R.; Webler, A. D. Qualidade da água de nascentes urbanas: estudo de caso em microbacia Amazônica, Município de Ji-Paraná/RO. Revista Ibero-

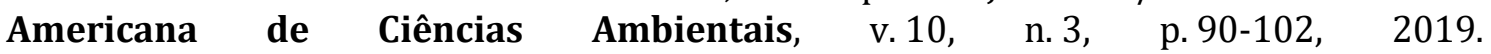
https://doi.org/10.6008/CBPC2179-6858.2019.003.0009

Silva, D. P. P.; Medeiros, P. S. M.; Caramello, N. Percepção de educadores sobre aspectos da educação ambiental em escolas do Município de Ji-Paraná-RO. Revista Ibero-Americana de Ciências Ambientais, v. 11, n. 6, p. 688-699, 2020. https://doi.org/10.6008/ CBPC2179-6858.2020.006.0055

Silva, S. C. S. e Lima, A. M. M. Análise do uso e ocupação da terra e sua influência na subbacia do Ji-Paraná. Revista Brasileira de Geografia Física, v. 12, n. 1, p. 201-212, 2019. https://doi.org/10.26848/rbgf.v12.1.p201-212

Sousa, L. M. S.; Lopez, D. S.; Mendonça, A. G.; Martins, W. R. D.; Rosa, A. L. D.; Gomes, B. M.; Nascimento, E. L. Análise das variáveis limnológicas do Igarapé Mangueira, Município Ji-Paraná-RO. South American Journal of Basic Education, Technical and Technological, v. 6, supl. 7, p. 71-83, 2019.

Tonso, S. Diálogo e educação ambiental no campo das águas. In: De Paula-Júnior, F.; Modaelli, S. (Org.). Política de águas e educação ambiental: processos dialógicos e formativos em planejamento e gestão de recursos hídricos. Brasília: MMA/SRHU, 2013.

Valadão, C.C.; Aguiar, R. G.; Webler, A. D. Padrão da chuva em áreas de floresta e pastagem no sudoeste da Amazônia. South American Journal of Basic Education, Technical and Technological, v. 6, supl. 7, p. 244-260, 2019.

Informação da Licença: Este é um artigo Open Access distribuído sob os termos da Licença Creative Commons Attribution, que permite uso irrestrito, distribuição e reprodução em qualquer meio, desde que a obra original seja devidamente citada. 